\title{
Determinants of Obtaining COVID-19 Vaccination among Health Care Workers with Access to Free COVID-19 Vaccination: A Cross-Sectional Study
}

\author{
Mariam R. Elkhayat ${ }^{1, *}$, Maiada K. Hashem ${ }^{2}$, Ahmed T. Helal ${ }^{3,4}$, Omar M. Shaaban ${ }^{5}$, Ahmed K. Ibrahim ${ }^{6}$, \\ Taghreed S. Meshref ${ }^{7}$, Hussein Elkhayat ${ }^{8}$ (D), Mohamed Moustafa ${ }^{9}$, Mohammed Nahed Attia Mohammed ${ }^{10}$,
} Azza M. Ezzeldin 11, Hebatallah G. Rashed ${ }^{11}$, Alaa Bazeed ${ }^{1}$, Islam H. Ibrahim ${ }^{12}$, Ahmed Mokhtar Mahmoud ${ }^{12} \mathbb{D}_{\text {, }}$ Moaiad Eldin Ahmed Mohamed ${ }^{12}$, Reem Sayad ${ }^{12}$ and Shimaa A. Elghazally ${ }^{1}$

1 Occupational and Environmental Medicine Department, Assiut University, Assiut 71526, Egypt; alaabazeed@med.aun.edu.eg (A.B.); shima_dola@aun.edu.eg (S.A.E.)

2 Chest Disease Department, Faculty of Medicine, Assiut University, Assiut 71526, Egypt; maiada.hashem@aun.edu.eg

3 Social Casework Department, Faculty of Social Work, Assiut University, Assiut 71514, Egypt; ahmed.socialwork@aun.edu.eg

4 Sociology and Social Work Department, College of Arts and Social Science, Sultan Qaboos University, Muscat 123, Oman

5 Department of Obstetrics and Gynecology, Faculty of Medicine, Assiut University Hospital, Assiut 71526, Egypt; omshaaban2000@aun.edu.eg

6 Public Health Department, Faculty of Medicine, Assiut University, Assiut 71526, Egypt; ahmed.ibrahim@aun.edu.eg

check for updates

Citation: Elkhayat, M.R.; Hashem, M.K.; Helal, A.T.; Shaaban, O.M.; Ibrahim, A.K.; Meshref, T.S.;

Elkhayat, H.; Moustafa, M.;

Mohammed, M.N.A.; Ezzeldin, A.M.; et al. Determinants of Obtaining COVID-19 Vaccination among Health Care Workers with Access to Free COVID-19 Vaccination: A Cross-Sectional Study. Vaccines 2022, 10, 39. https://doi.org/10.3390/ vaccines10010039

Academic Editor: Vincenzo Baldo

Received: 28 October 2021

Accepted: 18 December 2021

Published: 29 December 2021

Publisher's Note: MDPI stays neutral with regard to jurisdictional claims in published maps and institutional affiliations.

Copyright: () 2021 by the authors. Licensee MDPI, Basel, Switzerland. This article is an open access article distributed under the terms and conditions of the Creative Commons Attribution (CC BY) license (https:// creativecommons.org/licenses/by/ $4.0 /)$.
7 Critical Care Unit, Department of Internal Medicine, Faculty of Medicine, Assiut University, Assiut 71526, Egypt; tagreed.meshref@aun.edu.eg

8 Cardiothoracic Surgery Department, Faculty of Medicine, Assiut University, Assiut 71526, Egypt; elkhayat@aun.edu.eg

9 Orthopedics and Trauma Surgery, Faculty of Medicine, Assiut University, Assiut 71526, Egypt; mohamed.m.alaa@aun.edu.eg

10 Oral \& Maxillofacial Surgery, Faculty of Dentistry, Assiut University, Assiut 71526, Egypt; mohammed_nahed@aun.edu.eg

11 Clinical Pathology Department, Assiut University Hospital, Assiut 71526, Egypt; azzam80@aun.edu.eg (A.M.E.); h.rashed64@aun.edu.eg (H.G.R.)

12 Faculty of Medicine, Assiut University, Assiut 71526, Egypt; Islam.16266300@med.aun.edu.eg (I.H.I.); ahmedmokhtarmahmoud98@gmail.com (A.M.M.); moide1998@gmail.com (M.E.A.M.); reemoo.8527@gmail.com (R.S.)

* Correspondence: mariam.elkhayat@aun.edu.eg

Abstract: Introduction: Despite global efforts to contain the illness, COVID-19 continues to have severe health, life, and economic repercussions; thus, maintaining vaccine development is mandatory. Different directions concerning COVID-19 vaccines have emerged as a result of the vaccine's unpredictability. Aims: To study the determinants of the attitudes of healthcare workers (HCWs) to receiving or refusing to receive the vaccine. Methods: The current study adopted an interviewed questionnaire between June and August 2021. A total of $341 \mathrm{HCWs}$ currently working at Assiut University hospitals offered to receive the vaccine were included. Results: Only half of the HCWs (42\%) accepted the COVID-19 vaccine. The most common reason that motivated the HCWs was being more susceptible than others to infection (71.8\%). On other hand, the common reasons for refusing included: previously contracted the virus $(64.8 \%)$; did not have time (58.8\%); warned by a doctor not to take it (53.8\%). Nearly one-third of nonaccepting HCWs depended on television, the Internet, and friends who refused the vaccine for information $(p<0.05)$. In the final multivariate regression model, there were six significant predictors: sex, job category, chronic disease, being vaccinated for influenza, and using Assiut University hospital staff and the Ministry of Health as sources of information $(p<0.05)$. Conclusion: Misinformation and negative conceptions are still barriers against achieving the desired rate of vaccination, especially for vulnerable groups such as HCWs.

Keywords: health care workers; COVID-19; vaccine 


\section{Introduction}

Egypt ranks fourth in terms of population, holding 105 million people based on projections of the latest United Nations data, with an Asyut population of 420,585. In 2018, the median age of the population reached 23.9 years. Based on 2017 estimates, there are about $37.6 \%$ between $25-54$ years of age (the working age) [1], with the presence of about 100,000 doctors and 132,000 nurses working in governmental hospitals all over Egypt [2] However, the CFR percentage in Egypt (5.92\%), and, as Dr. Hala Zayed, the Minister of Health and Population, confessed, the COVID-19 infection rate among the Egyptians is much more than what the government has quantified. This is attributed to the high numbers of infected cases in Egypt which pass as officially undetected and recovered at home [3].

Despite global efforts to contain the illness (physical separation, face masking, travel restrictions, and quarantine), COVID-19 continues to have severe health, life, and economic repercussions [4]. The world's aspirations are tied to an effective preventive strategy and vaccination, which has demonstrated its potential to prevent illnesses and save lives over time [5]. Several vaccines began to emerge near the end of 2020. There are approximately 100 potential vaccines, with the most widely distributed six candidate vaccines presently in the third phase of testing. Their composition, storage needs, and effectiveness are all different (ranging from $70.4 \%$ to $95 \%$ ) [6]. Different directions, views, and attitudes concerning COVID-19 vaccines have emerged as a result of the vaccine's unpredictability. Governments and public health specialists face issues because of these discrepancies. Vaccination apprehension has been named one of the top ten global health challenges by the World Health Organization (WHO) [7]. Many studies from the United States of America (USA) [8], China [9], the United Kingdom, Ireland [10], and Congo [11] found varying levels of vaccination acceptability and hesitation among the general public and healthcare staff. The greatest rates of reluctance were among participants from the western areas of the Arab world according to a multicentric research study including Arab nations that measured HCWs' trepidation about vaccination (Egypt, Tunisia, Algeria, and Morocco) [12].

Since December 2020, Egypt began to receive shipments of anti-COVID-19 vaccines, such as Sinopharm (BBIBP-CorV), AstraZeneca vaccine, and Sputnik V. Priority groups for vaccination are (A) medical staff at quarantine, fever, and chest hospitals; (B) patients with cancer, kidney, or immunity problems, chronic disease patients, and the elderly; (C) and eventually all citizens above 18 years of age. As of March 2021, Egypt has started COVID-19 vaccine rollouts. The country aims to vaccinate $40 \%$ of its population against COVID-19 by the end of 2021 [1].

We must quantify vaccine reluctance and understand the specific grounds behind it in order to tackle the projected impending issue of vaccination hesitancy.

Recently, and as a part of the national program of vaccination, the governmental health authority offered an extreme priority and free COVID-19 vaccination to all those who are accepting from the Assiut University Hospital, including doctors, nurses, workers, and employees.

This work is designed to study the attitudes and the determinants of the attitudes of those groups of the population receiving or refusing to receive their first dose of vaccination.

\section{Materials and Methods}

\subsection{Study Design and Site}

A cross-sectional study was conducted among healthcare workers currently working in Assiut University hospitals (Dental, Obstetrics and Gynecology, main building, and Cardiac) and who were offered to receive the first dose of AstraZeneca and the Sinopharm vaccine. This study aimed to determine the attitudes and to assess the main contributing factors for receiving or refusing to receive the first dose of vaccination. The study was conducted in the period between June and August 2021.

Sample size calculation was carried out using the EPI Info 2000 statistical package. The calculation was based on an expected frequency for acceptance among Egyptian healthcare 
workers to the COVD-19 vaccine (21\%) [3] during a COVID-19 attack, with a difference of $5 \%$ and a confidence interval of $95 \%$. The minimum required sample was 255 . The sample was raised to $341 \mathrm{HCWs}$ to compensate for refusals and incomplete data. The sampling technique was multistage, where in the first stage there was a simple random sampling so to choose 4 hospitals from 8 hospitals, i.e., a sample in each hospital was proportionate to the size of the number of HCWs working in it (the total in 4 hospitals was 7233, where the main hospital represented $46 \%$ of the total, and we took $159 \mathrm{HCWs}$, which represented the same percentage from the total sample). Then, in each hospital a convenience sampling technique was applied, as all HCWs had same call and chance for obtaining their vaccine (Figure 1). A questionnaire was applied via the interview method.

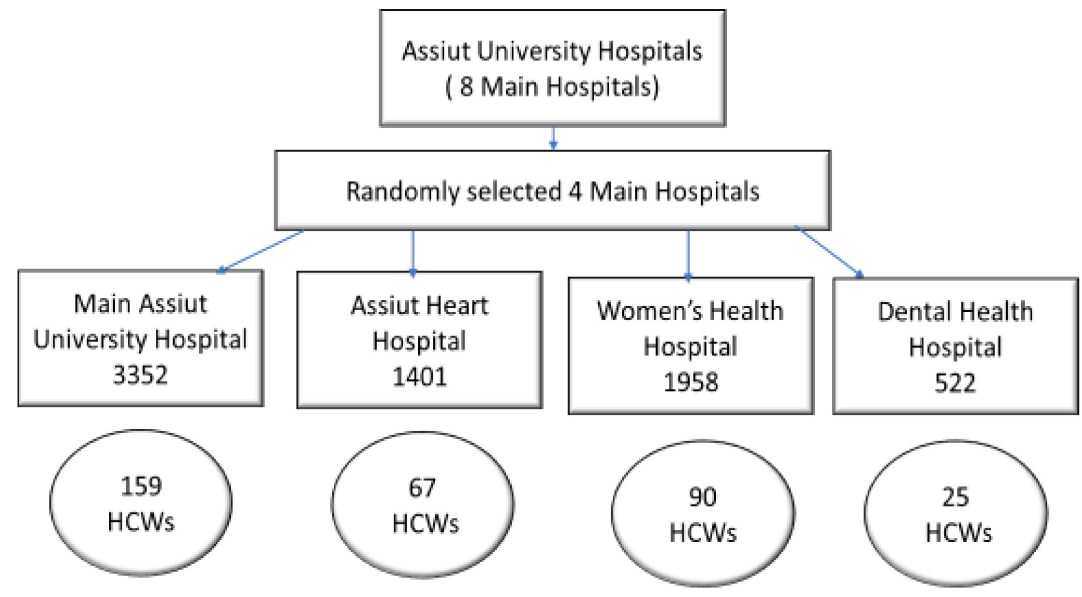

Figure 1. Flow chart of recruited healthcare workers in Assiut University hospitals.

\subsection{Data Collection Tools}

A predesigned interviewed questionnaire was prepared for the assessment of the attitudes and the determinants of the attitudes of these groups of the population for receiving or refusing to receive their first dose of vaccination.

The questionnaire was composed of different parts, as follows:

Personal history, including name, age, residency, marital status, and comorbidity conditions such as diabetes mellitus (DM) and hypertension (HTN).

Previous history of infection with COVID-19 within 3 months or the infection of a family member, and the exposure assessment was detected by asking about the number of attendances in COVID-19 isolation areas and the number of exposures to confirmed COVID-19 patients.

Asking the HCWs who were offered the COVID-19 vaccination if they accepted it or not, and the determinants of their decision. HCWs who accepted were asked 17 questions collected from previous studies [3,12], and each had to answer "yes", "no", or "maybe", with a Cronbach's alpha of 0.709. Nonaccepting HCWs were asked questions collected from previous studies $[13,14]$, and each had to answer "yes", "no", or "maybe", with a Cronbach's alpha of 0.829 .

The degree of acceptance of the HCWs who accepted vaccination was determined by two main questions which were asked to the participants: (i) their willingness to be vaccinated themselves and (ii) their willingness to recommend the vaccines to their patients, using a five-point scale from 'no, certainly not' and 'no, probably not' to 'yes, probably', and 'yes, certainly', with a 'do not know' option. A score of the presumptive acceptance of future COVID-19 vaccines was constructed based on the responses to the two questions in the survey about COVID-19 vaccines. The score was derived from awarding points per participant depending on the different possible responses given, with zero points for an answer 'no, certainly not', one point for 'no, probably not', two points for 'yes, probably', and three points for 'yes, certainly'. 'Do not know' answers did not get any points and were considered separately. The points obtained for each of the two questions 
per participant were then summed to obtain the score (Cronbach's alpha: 0.83 ; range: $0-6$ ). We then used the score to categorize participants according to their degree of 'COVID-19 vaccine acceptance': 'high acceptance' (score $>4$ ), 'moderate acceptance' (score $=4$ ), and 'hesitancy or reluctance (to score $<4$, or answers 'do not know' to at least one of the two questions) [15].

The opinion of the HCWs toward the system of vaccine application, which was illustrated to all HCWs offered the vaccine, was rated on the Likert scale from 0 to 10 and was classified as bad (0 to 4$)$, moderate (5 and 6), and good (7 to 10).

\subsection{Procedures}

A thorough literature review was conducted by the authors for the questionnaire design. For data collection, 4 training settings were performed by qualified researchers, then the pilot study was done with only 10 questionnaires and was not included in the analysis so to test the questionnaire questions and the time consumed. Moreover, during data collection, several sudden audit visits were performed by trainee researchers to data collectors so to assure the data collection. Then, the questionnaire was filled out by the trained data collector from the assigned HCWs at Assiut University hospitals by interviewing them. Each interview took about 15-20 min, after discussing the aim of research and confirming their acceptance to share in the research.

\subsection{Statistical Tests}

Data was analyzed using the SPSS software package version 21 (IBM-SPSS Inc., Chicago, IL, USA). Descriptive statistics were performed as frequency and cross tabulations for categorical variables. The Chi-square test was used to compare the independent categorical variables. Logistic regression was carried out to evaluate the possible attitude correlates. The significant $p$-value was set at a 0.05 cutoff.

\section{Results}

3.1. Sociodemographics, Job Categories, Chronic Diseases, Previous COVID-19 Infection and Exposure, and Main Sources of Information Differences among Accepting and Nonaccepting HCWs to COVID-19 Vaccine

The current research adopted an observational cross-sectional design to determine the attitude of HCWs regarding the COVID-19 vaccine. A total 341 completed questionnaires were included for the final analysis. The mean participants' age was about $34 \pm 9.27$. The female/male ratio was about 1:2 (38\%/62\%). Likely, the single to married ratio was 1:2. Most of them (59\%) had an urban residence. The cohort of HCWs were classified as $37 \%$ nurses, $31 \%$ doctors, $13.8 \%$ administrators, $12 \%$ workers and assistant nurses, and $6 \%$ pharmacists and technicians (Table 1 ).

All sociodemographic characteristics (age, sex, residence, and marital status) were a significant predictor for accepting the vaccine. Young (18-<30), male, urban, and single HCWs had a higher acceptance. Moreover, job category had significant effect on vaccine acceptance, as two-thirds of the accepting HCWs were physicians $(60.6 \%)$ versus only $16.2 \%$ nurses and $4.9 \%$ workers and assistant nurses. A previous history of receiving an influenza vaccine was an important predictor for COVID-19 vaccination, as two-thirds (66.3\%) of those nonaccepting of the vaccine were vaccinated from influenzas, versus half of those accepting the COVID-19 vaccine were not vaccinated from influenzas $(p<0.05)$. Regarding exposure to COVID-19, having shifts in COVID-19 isolation areas had no significant effect on accepting the COVID-19 vaccine ( $p>0.05$ ), while the number of exposures of HCWs to confirmed COVID-19 patients had a significant effect on their acceptance to the COVID-19 vaccine, as $55.6 \%$ of accepting HCWs were exposed more than three times to COVID-19 patients vs. $32.2 \%$ of nonaccepting HWCs who were exposed more than three times. nearly one-third of the nonaccepting HCWs depend on television, the Internet, and friends who refuse vaccine for information $(p<0.05)$; on the opposite side, nearly $60 \%$ the accepting HCWs depend on international organizations and the Assiut medical staff for information $(p<0.05)$ (Table 1). 
Table 1. Sociodemographic, job categories, chronic diseases, previous COVID-19 infection and exposure, and main sources of information differences among accepting and nonaccepting HCWs to COVID-19 vaccine $(\mathrm{N}=341)$.

\begin{tabular}{|c|c|c|c|c|}
\hline Characteristics & $\mathbf{N}(\%)$ & $\begin{array}{c}\text { Accepting } \\
\mathrm{N}=142\end{array}$ & $\begin{array}{l}\text { Nonaccepting } \\
\quad \mathrm{N}=199\end{array}$ & $p$-Value * \\
\hline \multicolumn{5}{|l|}{ Age categories } \\
\hline $18-<30$ & $145(42.5 \%)$ & $74(52.1 \%)$ & $71(35.7 \%)$ & 0.003 \\
\hline $30-<50$ & $167(49.0 \%)$ & $54(38.0 \%)$ & $113(56.8 \%)$ & \\
\hline $50-61$ & $29(8.5 \%)$ & $14(9.9 \%)$ & $15(7.5 \%)$ & \\
\hline \multicolumn{5}{|l|}{ Sex } \\
\hline Male & $131(38.4 \%)$ & $89(62.7 \%)$ & $42(21.1 \%)$ & $<0.001$ \\
\hline Female & $210(61.6 \%)$ & $53(37.3 \%)$ & $157(78.9 \%)$ & \\
\hline \multicolumn{5}{|l|}{ Residence } \\
\hline Rural & $86(25.2 \%)$ & $24(16.9 \%)$ & $62(31.2 \%)$ & 0.006 \\
\hline Urban & $202(59.2 \%)$ & $97(68.3 \%)$ & $105(52.8 \%)$ & \\
\hline Rural/Urban & $53(15.5 \%)$ & $21(14.8 \%)$ & $32(16.1 \%)$ & \\
\hline \multicolumn{5}{|l|}{ Marital status } \\
\hline Single & $126(37.0 \%)$ & $73(51.4 \%)$ & $53(26.6 \%)$ & $<0.001$ \\
\hline Married & $215(63.0 \%)$ & $69(48.6 \%)$ & $146(73.4 \%)$ & \\
\hline \multicolumn{5}{|l|}{ Job categories } \\
\hline Doctors & $106(31.1 \%)$ & $86(60.6 \%)$ & $20(10.1 \%)$ & $<0.001$ \\
\hline Nurses & $126(37.0 \%)$ & $23(16.2 \%)$ & $103(51.8 \%)$ & \\
\hline Workers/Assistant nurses & $41(12 \%)$ & $7(4.9 \%)$ & $34(17.1 \%)$ & \\
\hline Admin & $47(13.8 \%)$ & $19(13.4 \%)$ & $28(14.1 \%)$ & \\
\hline Pharmacists, lab technicians, and chemists & $21(6.2 \%)$ & $7(4.9 \%)$ & $14(7.0 \%)$ & \\
\hline \multicolumn{5}{|l|}{ Hospitals } \\
\hline Main Assiut University Hospital & $159(46.6 \%)$ & $69(48.6 \%)$ & $90(45.2 \%)$ & 0.104 \\
\hline Assiut Heart Hospital & $67(19.6 \%)$ & $32(22.5 \%)$ & $35(17.6 \%)$ & \\
\hline Women Health Hospital & $90(26.4 \%)$ & $36(25.4 \%)$ & $54(27.1 \%)$ & \\
\hline Dental Health Hospital & $25(7.3 \%)$ & $5(3.5 \%)$ & $20(10.1 \%)$ & \\
\hline History of chronic disease & $50(14.7 \%)$ & $20(14.1 \%)$ & $30(15.1 \%)$ & 0.799 \\
\hline History of previous COVID-19 infection & $77(22.6 \%)$ & $36(25.4 \%)$ & $41(20.6 \%)$ & 0.301 \\
\hline History of family COVID-19 infection & $77(22.6 \%)$ & $43(30.3 \%)$ & $34(17.1 \%)$ & 0.004 \\
\hline \multicolumn{5}{|l|}{ History of influenza vaccination } \\
\hline Yes & $133(39 \%)$ & $66(46.5 \%)$ & $67(33.7 \%)$ & 0.017 \\
\hline No & $208(61 \%)$ & $76(53.5 \%)$ & $132(66.3 \%)$ & \\
\hline \multicolumn{5}{|l|}{ Had shifts in COVID-19 isolation area } \\
\hline Never & $221(64.8 \%)$ & $93(65.5 \%)$ & $128(64.3 \%)$ & 0.123 \\
\hline Once & $33(9.7 \%)$ & $8(5.6 \%)$ & $25(12.6 \%)$ & \\
\hline Twice & $11(3.2 \%)$ & $3(2.1 \%)$ & $8(4.0 \%)$ & \\
\hline Three times & $2(0.6 \%)$ & $1(0.7 \%)$ & $1(0.5 \%)$ & \\
\hline More than three times & $74(21.7 \%)$ & $37(26.1 \%)$ & $37(18.6 \%)$ & \\
\hline
\end{tabular}


Table 1. Cont.

\begin{tabular}{|c|c|c|c|c|}
\hline Characteristics & $\mathbf{N}(\%)$ & $\begin{array}{c}\text { Accepting } \\
\mathrm{N}=142\end{array}$ & $\begin{array}{c}\text { Nonaccepting } \\
\quad \mathrm{N}=199\end{array}$ & $p$-Value * \\
\hline \multicolumn{5}{|c|}{ Times exposed to confirmed COVID-19 patients } \\
\hline Never & $116(34.0 \%)$ & $34(23.9 \%)$ & $82(41.2 \%)$ & $<0.001$ \\
\hline Once & $51(15.0 \%)$ & $15(10.6 \%)$ & $36(18.1 \%)$ & \\
\hline Twice & $24(7.0 \%)$ & $11(7.7 \%)$ & $13(6.5 \%)$ & \\
\hline Three times & $7(2.1 \%)$ & $3(2.1 \%)$ & $4(2.0 \%)$ & \\
\hline More than three times & $143(41.9 \%)$ & $79(55.6 \%)$ & $64(32.2 \%)$ & \\
\hline \multicolumn{5}{|c|}{ Attend COVID-19 vaccine awareness sessions in Assiut University hospitals } \\
\hline Yes & $64(18.8 \%)$ & $30(21.1 \%)$ & $34(17.1 \%)$ & $<0.001$ \\
\hline No & $167(49.0 \%)$ & $52(36.6 \%)$ & $115(57.8 \%)$ & \\
\hline Never hear about it & $110(32.3 \%)$ & $60(42.3 \%)$ & $50(25.1 \%)$ & \\
\hline \multicolumn{5}{|c|}{ Main source of scientific information regarding COVID-19 vaccine } \\
\hline International organization & $140(41.1 \%)$ & $81(57.0 \%)$ & $59(29.6 \%)$ & $<0.001$ \\
\hline Assiut medical staff & $173(50.7 \%)$ & $82(57.7 \%)$ & $91(45.7 \%)$ & 0.029 \\
\hline Television & $90(26.4 \%)$ & $19(13.4 \%)$ & $71(35.7 \%)$ & $<0.001$ \\
\hline Friends & $73(21.4 \%)$ & $19(13.4 \%)$ & $54(27.1 \%)$ & 0.002 \\
\hline Research papers & $73(21.4 \%)$ & $43(30.3 \%)$ & $30(15.1 \%)$ & 0.001 \\
\hline Facebook and social media & $102(29.9 \%)$ & $31(21.8 \%)$ & $71(35.7 \%)$ & 0.006 \\
\hline Health Ministry website & $65(19.1 \%)$ & $21(14.8 \%)$ & $44(22.1 \%)$ & 0.159 \\
\hline Scientific lectures & $38(11.1 \%)$ & $16(11.3 \%)$ & $22(11.1 \%)$ & 0.951 \\
\hline
\end{tabular}

${ }^{*}$ Chi-square test, bold $p$-values were significant $(p<0.05)$.

3.2. Frequency of Accepting and Nonaccepting Cohort of HCWs toward COVID-19 Vaccine, and Frequency of Regret of HCWs among the Accepting Ones

Figure 2 revealed that nearly half of the HCWs, 42\% (95\% CI: 38: 46), accepted the COVID-19 vaccine, and only 5\% (95\% CI: 3:7) of them felt regret.

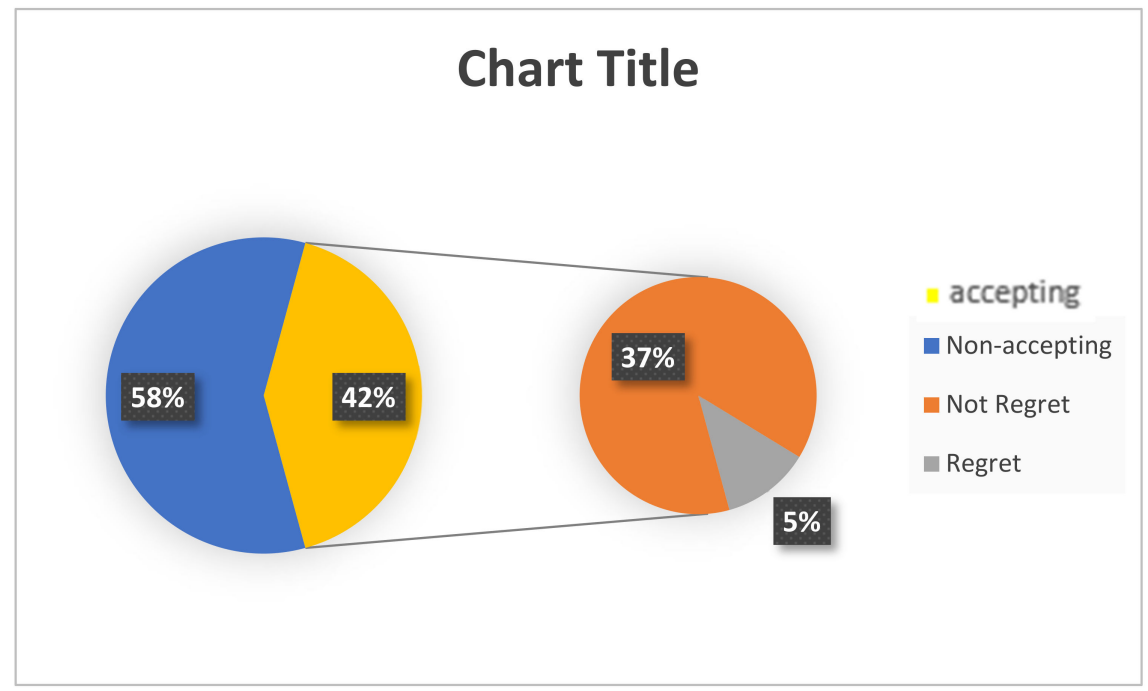

Figure 2. Frequency of accepting and nonaccepting cohort HCWs toward COVID-19 vaccine, and frequency of regret among the accepting HCWs. 


\subsection{Predictors of Vaccine Acceptance among Accepted HCWs}

The most common reasons that motivated the HCWs to obtain their COVID-19 vaccine were: being more susceptible than others to infection (71.8\%); vaccination is a collective action to prevent the spread of disease $(68.3 \%)$; the vaccine will help me not to get the virus $(64.8 \%)$; the vaccine will help me not to infect those around me with the virus $(64.8 \%)$; the benefits of the vaccine are much greater than its harm $(60.6 \%)$, while the lowest cause was receiving the vaccine from the recommendation of a family member $(16.8 \%)$ (Table 2). The majority (83.5\%) had a high degree of acceptance toward the COVID-19 vaccine (95\% CI: 81:86). Moreover, two-thirds (65.7\%) stated that the system of vaccine application was good.

Table 2. Predictors of vaccine acceptance among accepted HCWs $(\mathrm{N}=142)$.

\begin{tabular}{|c|c|c|c|}
\hline Predictors for Vaccine Acceptance $(\mathrm{N}=142)$ & Yes & No & "Maybe" \\
\hline Is taking vaccine is mandatory and practical & $83(58.5 \%)$ & $27(19.0 \%)$ & $32(22.5 \%)$ \\
\hline I think the vaccine will help me not get the virus & $92(64.8 \%)$ & $8(5.6 \%)$ & $42(29.6 \%)$ \\
\hline $\begin{array}{l}\text { I think that the vaccine will help me not to infect those around me } \\
\text { with the virus }\end{array}$ & $92(64.8 \%)$ & $13(9.2 \%)$ & $37(26.1 \%)$ \\
\hline I suffer from a chronic disease, so I took the vaccine for fear of my life & $29(20.4 \%)$ & $92(64.8 \%)$ & $21(14.8 \%)$ \\
\hline $\begin{array}{l}\text { My trust in the manufacturer of the vaccine that I took encouraged } \\
\text { me to take the vaccine }\end{array}$ & $24(16.9 \%)$ & $42(29.6 \%)$ & $76(53.5 \%)$ \\
\hline $\begin{array}{l}\text { I took the vaccine because I was afraid that I would not get it in } \\
\text { the future }\end{array}$ & $38(26.8 \%)$ & $51(35.9 \%)$ & $53(37.3 \%)$ \\
\hline $\begin{array}{l}\text { I took the vaccine because it was recommended by international } \\
\text { scientific agencies }\end{array}$ & $74(52.1 \%)$ & $19(13.4 \%)$ & $49(34.5 \%)$ \\
\hline I believe that there are no serious side effects from taking the vaccine & $37(26.1 \%)$ & $38(26.8 \%)$ & $67(47.2 \%)$ \\
\hline I think that the benefits of the vaccine are much more than its harm & $86(60.6 \%)$ & $11(7.7 \%)$ & $45(31.7 \%)$ \\
\hline I took the vaccine as a recommendation of a doctor I trust & $51(35.9 \%)$ & $40(28.2 \%)$ & $51(35.9 \%)$ \\
\hline I took the vaccine as a recommendation of a trusted friend/person & $35(24.6 \%)$ & $49(34.5 \%)$ & $58(40.8 \%)$ \\
\hline I took the vaccine as a recommendation of a member of my family & $23(16.2 \%)$ & $68(47.9 \%)$ & $51(35.9 \%)$ \\
\hline $\begin{array}{l}\text { I believe that vaccination is a collective action to prevent the spread } \\
\text { of disease }\end{array}$ & $97(68.3 \%)$ & $9(6.3 \%)$ & $36(25.4 \%)$ \\
\hline $\begin{array}{l}\text { I am confident that the public authorities decide the best interest } \\
\text { for society }\end{array}$ & $63(44.4 \%)$ & $18(12.7 \%)$ & $61(43.0 \%)$ \\
\hline $\begin{array}{l}\text { The continuous increase of cases around me made me not hesitate to } \\
\text { take the vaccine }\end{array}$ & $84(59.2 \%)$ & $11(7.7 \%)$ & $47(33.1 \%)$ \\
\hline $\begin{array}{l}\text { I feel that I am more susceptible than others to infection due to the } \\
\text { nature of my work }\end{array}$ & $102(71.8 \%)$ & $11(7.7 \%)$ & $29(20.4 \%)$ \\
\hline $\begin{array}{l}\text { What I heard and saw on the Internet and social networks about the } \\
\text { vaccine encourage me take it }\end{array}$ & 57 (40.1\%) & $31(21.8 \%)$ & $54(38.0 \%)$ \\
\hline
\end{tabular}

\subsection{Predictors of Vaccine Nonacceptance among Nonaccepted HCWs}

On the other hand, Table 3 revealed what the most common reasons for refusing the COVID-19 vaccine were: recently contracted the virus and do not need the vaccine $(64.8 \%)$; I do not have enough time to take the vaccine $(58.8 \%)$; warned by a doctor not to take the vaccine (53.8\%); the infection with the coronavirus is not so severe that I should receive the vaccine $(49.7 \%)$; however, the lowest cause concerned the side effects/complications that may happen to me if I take the vaccine (3\%) (Table 3$)$. 
Table 3. Predictors of vaccine nonacceptance among nonaccepted HCWs ( $=199)$.

\begin{tabular}{|c|c|c|c|}
\hline Predictors for Vaccine Nonacceptance $(\mathrm{N}=199)$ & No & Yes & "Maybe" \\
\hline I think, if I took the vaccine, I might catch COVID-19 infection & $40(20.1 \%)$ & $89(44.7 \%)$ & $70(35.2 \%)$ \\
\hline $\begin{array}{l}\text { I don't think there is an effective vaccine in avoiding infection with } \\
\text { the virus COVID-19 }\end{array}$ & $29(14.6 \%)$ & $100(50.3 \%)$ & $70(35.2 \%)$ \\
\hline $\begin{array}{l}\text { I am concerned about the side effects/complications that may } \\
\text { happen to me if I take the vaccine }\end{array}$ & $6(3.0 \%)$ & $147(73.9 \%)$ & $46(23.1 \%)$ \\
\hline $\begin{array}{l}\text { I refused because of the request to sign for the responsibility in case I } \\
\text { was given a vaccine }\end{array}$ & $83(41.7 \%)$ & $69(34.7 \%)$ & $47(23.6 \%)$ \\
\hline $\begin{array}{l}\text { My lack of confidence in the healthcare system followed in } \\
\text { my country }\end{array}$ & $71(35.7 \%)$ & $64(32.2 \%)$ & $64(32.2 \%)$ \\
\hline I do not trust the manufacturers of this vaccine & $45(22.6 \%)$ & $88(44.2 \%)$ & $66(33.2 \%)$ \\
\hline $\begin{array}{l}\text { I think that the emerging coronavirus is a threat that has been } \\
\text { amplified, and therefore there is no need to take a vaccine }\end{array}$ & $93(46.7 \%)$ & $39(19.6 \%)$ & $67(33.7 \%)$ \\
\hline I am a precautionary person, so I do not need to take the vaccine & $42(21.1 \%)$ & $79(39.7 \%)$ & $78(39.2 \%)$ \\
\hline I recently contracted the virus and do not need the vaccine & $129(64.8 \%)$ & $32(16.1 \%)$ & $38(19.1 \%)$ \\
\hline I was warned by a doctor not to take the vaccine & $107(53.8 \%)$ & $49(24.6 \%)$ & $43(21.6 \%)$ \\
\hline I received a warning from someone around me not to take the vaccine & $79(39.7 \%)$ & $74(37.2 \%)$ & $46(23.1 \%)$ \\
\hline $\begin{array}{l}\text { What I heard and saw on the Internet and social networks about the } \\
\text { vaccine made me reject it }\end{array}$ & $58(29.1 \%)$ & $86(43.2 \%)$ & $55(27.6 \%)$ \\
\hline $\begin{array}{l}\text { The difficulty of the procedures followed in taking the vaccine } \\
\text { prevented me from taking it }\end{array}$ & $81(40.7 \%)$ & $45(22.6 \%)$ & $73(36.7 \%)$ \\
\hline $\begin{array}{l}\text { My lack of confidence in the safety of vaccines, as there are no proven } \\
\text { studies so far on the benefits and side effects of the vaccine }\end{array}$ & $25(12.6 \%)$ & $107(53.8 \%)$ & $67(33.7 \%)$ \\
\hline $\begin{array}{l}\text { My immune system is very strong, it also protects me from diseases, } \\
\text { and I do not need a vaccine }\end{array}$ & $79(39.7 \%)$ & $40(20.1 \%)$ & $80(40.2 \%)$ \\
\hline I do not have enough time to take the vaccine & $117(58.8 \%)$ & $29(14.6 \%)$ & $53(26.6 \%)$ \\
\hline $\begin{array}{l}\text { I think the infection with the coronavirus is not so severe that I } \\
\text { should receive the vaccine }\end{array}$ & 99 (49.7\%) & 38 (19.1\%) & $62(31.2 \%)$ \\
\hline $\begin{array}{l}\text { My fear of getting an infection while taking the vaccine prevented me } \\
\text { from taking it }\end{array}$ & $50(25.1 \%)$ & $85(42.7 \%)$ & $64(32.2 \%)$ \\
\hline $\begin{array}{l}\text { The safety of a vaccine developed in an emergency, during an } \\
\text { epidemic, cannot be guaranteed }\end{array}$ & $33(16.6 \%)$ & $102(51.3 \%)$ & $64(32.2 \%)$ \\
\hline $\begin{array}{l}\text { My belief in the superiority of acquiring immunity against infectious } \\
\text { diseases naturally, instead of taking the vaccine }\end{array}$ & 47 (23.6\%) & $83(41.7 \%)$ & $69(34.7 \%)$ \\
\hline
\end{tabular}

3.5. Multivariable Regression Analysis for the Main Predictors for Accepting COVID-19 Vaccine among the Offered Cohort of HCWs

Table 4 displayed the predictors of acceptance among the studied cohort. A total of 20 important predicting factors (with 16 significant factors by univariate analysis; Chisquare) and four other nonsignificant factors were added in the model, as having shifts in the COVID-19 isolation area, the presence of chronic diseases, using the Ministry of Health website, and reading lectures, due to their importance. After 11 models by backward, the final model contained eight predictors, where the significant predictors were: sex, job category, history of chronic disease, obtaining influenza vaccines, and the Assiut University hospital staff and Ministry of Health as the source of information. The HCWs vaccinated with influenza vaccines were 2.34 times more liable to accept the COVID-19 vaccine in comparison with those HCWs not previously vaccinated (AOR $=2.34,95 \%$ CI: $1.02-5.38$, $p$-value $<0.05)$, and this was statistically significant. Regarding the history of chronic disease, HCWs with chronic diseases were two times more liable to accept the COVID-19 vac- 
cines in comparison with the healthy HCWs (AOR $=2.34,95 \%$ CI: 1.02-5.38, $p$-value < 0.05), and this was statistically significant. Likewise, HCWs who depend on Assiut University staff as trusted sources of information were two times more liable to accept the COVID-19 vaccines $(\mathrm{AOR}=2.29,95 \% \mathrm{CI}: 1.25-4.21, p$-value $<0.05)$, and this was statistically significant. On the other hand, females were $62 \%$ more liable to refuse the vaccine than males $(\mathrm{AOR}=0.38,95 \%$ CI: $0.20-0.73, p$-value $<0.05)$.

Table 4. Multivariable regression analysis for the main predictors for accepting the COVID-19 vaccine among offered cohort HCWs.

\begin{tabular}{|c|c|c|c|c|}
\hline Variable & OR $(95 \% \mathrm{CI})$ & $p$-Value & AOR $(95 \% \mathrm{CI})$ & $p$-Value \\
\hline Age categories & $1.02(0.98: 1.06)$ & 0.463 & & \\
\hline Sex (F vs. M) & $0.48(0.24: 0.96)$ & 0.038 & $0.38(0.20: 0.73)$ & 0.003 \\
\hline Residence (R vs. U and mixed) & $1.29(0.79: 2.11)$ & 0.308 & & \\
\hline Marital status (S vs. M) & $0.49(0.24: 1.01)$ & 0.052 & $0.54(0.27: 1.04)$ & 0.065 \\
\hline Job categories (Doctors) & $\operatorname{Ref}[1]$ & $<0.001$ & Ref [1] & $<0.001$ \\
\hline Nurses & $0.05(0.2: 0.15)$ & $<0.001$ & $0.08(0.03: 0.18)$ & $<0.001$ \\
\hline Workers/assistant nurses & $0.04(0.01: 0.14)$ & $<0.001$ & $0.05(0.02: 0.14)$ & $<0.001$ \\
\hline Admin & $0.23(0.07: 0.71)$ & 0.010 & $0.27(0.11: 0.69)$ & 0.007 \\
\hline Pharmacists, lab technicians, and chemists & $0.09(0.03: 0.33)$ & $<0.001$ & $0.14(0.04: 0.42)$ & 0.001 \\
\hline History of chronic disease & $2.42(0.99: 5.88)$ & 0.052 & $2.34(1.02: 5.38)$ & 0.046 \\
\hline History of previous COVID-19 infection & $0.59(0.27: 1.29)$ & 0.187 & & \\
\hline History of family COVID-19 infection & $0.81(0.36: 1.78)$ & 0.596 & & \\
\hline History of influenzas' vaccination & $3.12(1.64: 5.93)$ & 0.001 & $2.83(1.56: 5.15)$ & 0.001 \\
\hline Had shifts in COVID-19 isolation area & $0.65(0.32: 1.31)$ & 0.232 & & \\
\hline Exposed to confirmed COVID-19 patients & $2.13(1.05: 4.32)$ & 0.038 & & \\
\hline $\begin{array}{l}\text { Attending COVID-19 vaccine awareness } \\
\text { sessions in Assiut University hospitals }\end{array}$ & $1.27(0.55: 2.94)$ & 0.574 & & \\
\hline \multicolumn{5}{|c|}{ Main source of information regarding COVID 19 vaccine } \\
\hline International organization & $1.21(0.57: 2.54)$ & 0.618 & & \\
\hline Assiut medical staff & $2.30(1.19: 4.45)$ & 0.013 & $2.29(1.25: 4.21)$ & 0.008 \\
\hline Television & $0.79(0.35: 1.73)$ & 0.556 & & \\
\hline Friends & $0.58(0.26: 1.34)$ & 0.205 & $0.53(0.25: 1.19)$ & 0.096 \\
\hline Research papers & $0.62(0.27: 1.44)$ & 0.270 & & \\
\hline Facebook and social media & $0.79(0.37: 1.71)$ & 0.561 & & \\
\hline Health Ministry website & $0.47(0.21: 1.05)$ & 0.066 & $0.48(0.23: 1.01)$ & 0.054 \\
\hline Scientific lectures & $2.19(0.81: 5.91)$ & 0.124 & & \\
\hline
\end{tabular}

F: female; M: male; R: rural; U: urban; S: single; M: married. bold $p$-values were significant $(p<0.05)$.

\section{Discussion}

Healthcare workers and their households are at a higher risk of getting COVID-19 infection $[16,17]$. With the absence of curative treatment for COVID-19 infection, vaccinating HCWs against COVID-19 is critical. However, variable degrees of acceptance to vaccination were reported [18]. In this study, nearly half $(42 \%)$ of the recruited HCWs accepted the vaccination. The majority (83.5\%) of them had a high acceptance degree toward the COVID-19 vaccine.

Earlier studies from Egypt reported lower acceptance rates, ranging from 21\% [4] to $26 \%$ [19]. Interestingly, the acceptance rate was reported to be $34.9 \%$ among Egyptian 
medical students [12]. The higher rate in the current study could be explained by the time of the data collection. Previous studies were carried out prior to start of the COVID-19 vaccination program in Egypt. Later, with actual vaccine administration, the availability of vaccines, easy access to the service, satisfaction about the vaccination application process, and tranquility regarding the short-term safety might contribute to increasing the acceptance rate.

This rate is also higher than others reported earlier in many low-, mid-, and even high-income countries in different geographic areas $[11,13,14,20]$. On the other hand, some studies have reported higher acceptance rates up to 70-90\% [21-25]. In line with our study, Qattan et al. [26] reported a moderate acceptance rate towards COVID-19 vaccination in KSA.

In agreement with most of the published literature $[11,24,27,28]$, physicians showed more acceptance to vaccination than other HCWs in the current study $(60.6 \%$ acceptance among physicians compared to $16.2 \%$ and $4.9 \%$ among nurses and workers, respectively). Generally speaking, higher levels of education are associated with a more positive attitude towards vaccination [29-31].

Age was not a predictor for COVID-19 vaccination acceptance in this study. However, younger participants (18-30 years old) had significantly higher acceptance rates. A study from Italy [32] reported associations between younger age and the intention to get vaccinated. Conversely, older age was found to have a significant association with a positive attitude towards COVID-19 vaccination in most of the published literature [13,14,19,27,33], which may be explained by the more severe impact of the pandemic with increasing age, and that older unvaccinated people are more likely to be hospitalized or die from COVID-19 [18]. This disagreement might be explained by the relative younger mean age of HCWs included in our studies (34 \pm 9.27 years), with only $8.5 \%$ of participants 50 years of age or more. Thus, the impact of older age with more comorbid diseases was not well estimated. However, we found that HCWs with chronic diseases were two times more liable to accept the COVID-19 vaccines in comparison with healthy workers.

Female healthcare workers were found to be $62 \%$ more liable to refuse the vaccine than the male workers included in the current study, which agreed with most previous studies $[13,14,34]$. This was likely due to their higher fear of side effects such as infertility, serious side effects making them unable to take care of their families, or greater susceptibility to myths and misinformation from media. On the other hand, males had better health-seeking behaviors and appreciation of advice about COVID-19 vaccines [18,35].

In line with a former report [21], healthcare workers who were previously vaccinated with the influenza vaccine were 2.34 times more liable to accept the COVID-19 vaccine in the current study. The behavior, knowledge, and attitude of HCWs toward influenza vaccination seemed to be similar to that toward COVID-19, being accepting or opposing to vaccination in general $[35,36]$. Moreover, some HCWs might believe in the role of the influenza vaccine in decreasing the risk of severe COVID-19 infection, besides reducing the risk of a coinfection of influenza and COVID-19 [37].

Investigators and analysts had focused on knowledge as a crucial factor controlling the behavior and attitudes of HCWs towards vaccination [38-40]. The source of the data influenced the degree to which the recipients incorporated this data into their decisionmaking process [41-43]. Healthcare workers' explanations or recommendations have a positive influence on the attitude toward the vaccine [21]. In the present study, HCWs who depend on Assiut University staff as a trusted source of information were two times more liable to accept the COVID-19 vaccines, with nearly $60 \%$ of accepting HCWs depending on international organizations and Assiut medical staff. Trust in the institutions from which information about vaccines was obtained is an essential driver of vaccine acceptance, for the general population and HCWs as well [43].

On the other hand, nearly two-thirds of HCWs depend on television, the Internet, and friends who refused the vaccine. These results agreed with previous a previous study from Egypt [19]. Moreover, unlike most of the previous publications which reported that 
concerns about the safety, efficacy, and side effects of the COVID-19 vaccines were the most prevalent reasons for vaccination refusal and hesitancy $[4,26,44,45]$, those were the lowest frequent causes to refuse vaccination in our study. Misinformation and false perceptions, including "I recently contracted the virus and do not need the vaccine; I do not have enough time to take the vaccine; I was warned by a doctor not to take the vaccine; the infection with the coronavirus is not so severe that I should receive the vaccine", were the most frequent causes. Thus, the impact of social media cannot be neglected, especially in less developed countries, nor can taking in the danger of the spread of misinformation across medias, which the WHO has named the "infodemic" [46].

In view of the foregoing, the negative attitude supported by misinformation possess an extra burden on the Egyptian government to achieve mass vaccination. Tailored programs encompassing different scientific and social modalities must be implemented in order to reach this target.

Even though the results of the current study express the actual situation regarding the attitude toward COVID-19 vaccination in Egypt, as all the accepting participants already received at least one dose of their scheduled vaccination and the study was performed by an interviewed, not online, questionnaire, it still has some limitations. The cross-sectional design of the study does not allow to follow the changing behavior of the participants toward the vaccine and its predictors. Besides, the study represents the attitude in a single healthcare facility in Upper Egypt. Thus, further prospective multicentric studies are recommended.

\section{Conclusions}

Healthcare worker attitudes toward COVID-19 vaccination in Egypt is improving, with higher acceptance rates than the prevaccination period. However, misinformation and negative conceptions are still barriers against achieving the desired rate of vaccination. Education and tailored interventions should be implemented to ensure that healthcare workers are vaccinated with the available COVID-19 vaccines.

\section{Strengths and Limitations}

The COVID-19 vaccination program is one of the most important concerns in the world for caring for and facing COVID-19 infection. Hesitency toward the COVID-19 vaccine is an important burden, so it is important to study, especially among the most vulnerable categories such as HCWs. One of the important limitations of this study is the duration of the exposure per visit of any COVID-19 case, which is an important factor that was not assessed, and a sampling technique which influences the representativeness of the results.

Author Contributions: Formal analysis, S.A.E., A.K.I. and M.R.E.; data collection, A.B., I.H.I., A.M.M., M.E.A.M., R.S., T.S.M., M.M., H.E. and M.N.A.M.; resources, M.K.H., A.T.H., O.M.S. and M.R.E.; data curation, S.A.E., A.K.I. and M.R.E.; writing—original draft preparation, M.K.H., S.A.E. and M.R.E.; writing-review and editing, M.K.H., H.E. and M.R.E.; visualization T.S.M., M.M. and M.N.A.M.; supervision, A.K.I. and O.M.S.; project administration, A.M.E. and H.G.R.; funding acquisition, none. All authors have read and agreed to the published version of the manuscript.

Funding: This research received no external funding.

Institutional Review Board Statement: The study was conducted according to the Declaration of Helsinki guidelines [47] and approved by clinical-trial registration website (NCT04924894) and the Assiut University ethical committee.

Informed Consent Statement: Informed consent was obtained from all subjects involved in the study.

Data Availability Statement: Data is available upon request for ethical purposes.

Acknowledgments: This paper has been written in the context of the research project "Immunization coverage among HCWs in Assiut University"; thus, we acknowledge Assiut University Hospital, 
Faculty of Medicine, Assiut University. The authors would like to thank all Healthcare workers of Assiut University hospitals who participated in this study.

Conflicts of Interest: The authors declare no conflict of interest.

\section{References}

1. Saied, A.A.; Metwally, A.A.; Madkhali, N.A.B.; Haque, S.; Dhama, K. Egypt's COVID-19 Recent Happenings and Perspectives: A Mini-Review. Front. Public Health 2021, 9, 696082. [CrossRef] [PubMed]

2. World Population Review. Egypt Population 2021 (Demographics, Maps, Graphs). 2021. Available online: Worldpopulationreview.com (accessed on 11 December 2021).

3. Egypt Data Portal. Number of Medical Facilities, Doctors and Nurses in the Governmental. Number of Medical Facilities, Doctors and Nurses in the Governmental, Private and Public Sectors-Egypt Data Portal. 2017. Available online: Opendataforafrica.org (accessed on 11 December 2021).

4. $\quad$ Fares, S.; Elmnyer, M.M.; Mohamed, S.S.; Elsayed, R. COVID-19 Vaccination Perception and Attitude among Healthcare Workers in Egypt. J. Prim. Care Community Health 2021, 12, 21501327211013303. [CrossRef] [PubMed]

5. Wang, K.; Wong, E.L.; Ho, K.F.; Cheung, A.W.; Yau, P.S.; Dong, D.; Wong, S.Y.-S.; Yeoh, E.-K. Change of Willingness to Accept COVID-19 Vaccine and Reasons of Vaccine Hesitancy of Working People at Different Waves of Local Epidemic in Hong Kong, China: Repeated Cross-Sectional Surveys. Vaccines 2021, 9, 62. [CrossRef] [PubMed]

6. Ferbeyre, G.; Santiago Vispo, N. The race for a coronavirus vaccine. Bionatura 2020, 5, 1290-1292. [CrossRef]

7. World Health Organization. Ten Threats to Global Health in 2019. 2019. Available online: https://www.who.int/news-room/ spotlight/ten-threats-to-global-health-in-2019 (accessed on 11 December 2021).

8. Pogue, K.; Jensen, J.L.; Stancil, C.K.; Ferguson, D.G.; Hughes, S.J.; Mello, E.J.; Burgess, R.; Berges, B.K.; Quaye, A.; Poole, B.D. Influences on Attitudes Regarding Potential COVID-19 Vaccination in the United States. Vaccines 2020, 8, 582. [CrossRef] [PubMed]

9. Lin, Y.; Hu, Z.; Zhao, Q.; Alias, H.; Danaee, M.; Wong, L.P. Understanding COVID-19 vaccine demand and hesitancy: A nationwide online survey in China. PLoS Negl. Trop. Dis. 2020, 14, e0008961. [CrossRef] [PubMed]

10. Murphy, J.; Vallieres, F.; Bentall, R.P.; Shevlin, M.; McBride, O.; Hartman, T.K.; McKay, R.; Bennett, K.; Mason, L.; Gibson-Miller, J.; et al. Psychological characteristics associated with COVID-19 vaccine hesitancy and resistance in Ireland and the United Kingdom. Nat. Commun. 2021, 12, 29. [CrossRef] [PubMed]

11. Kabamba Nzaji, M.; Kabamba Ngombe, L.; Ngoie Mwamba, G.; Banza Ndala, D.B.; Mbidi Miema, J.; Luhata Lungoyo, C.; Mwimba, B.L.; Betne, A.C.M.; Musenga, E.M. Acceptability of Vaccination Against COVID-19 Among Healthcare Workers in the Democratic Republic of the Congo. Pragmatic Obs. Res. 2020, 11, 103-109. [CrossRef] [PubMed]

12. Saied, S.M.; Saied, E.M.; Kabbash, I.A.; Abdo, S.A.E. Vaccine hesitancy: Beliefs and barriers associated with COVID-19 vaccination among Egyptian medical students. J. Med. Virol. 2021, 93, 4280-4291. [CrossRef]

13. Qunaibi, E.; Basheti, I.; Soudy, M.; Sultan, I. Hesitancy of Arab Healthcare Workers towards COVID-19 Vaccination: A Large-Scale Multinational Study. Vaccines 2021, 9, 446. [CrossRef]

14. Shekhar, R.; Sheikh, A.B.; Upadhyay, S.; Singh, M.; Kottewar, S.; Mir, H.; Barrett, E.; Pal, S. COVID-19 Vaccine Acceptance among Health Care Workers in the United States. Vaccines 2021, 9, 119. [CrossRef]

15. Verger, P.; Scronias, D.; Dauby, N.; Adedzi, K.A.; Gobert, C.; Bergeat, M.; Gagneur, A.; Dubé, E. Attitudes of healthcare workers towards COVID-19 vaccination: A survey in France and French-speaking parts of Belgium and Canada, 2020. Euro Surveill. 2021, 26, 2002047. [CrossRef]

16. Shah, A.S.V.; Wood, R.; Gribben, C.; Caldwell, D.; Bishop, J.; Weir, A.; Kennedy, S.; Reid, M.; Smith-Palmer, A.; Goldberg, D.; et al. Risk of hospital admission with coronavirus disease 2019 in healthcare workers and their households: Nationwide linkage cohort study. BMJ 2020, 371, m3582. [CrossRef]

17. Chou, R.; Dana, T.; Buckley, D.I.; Selph, S.; Fu, R.; Totten, A.M. Epidemiology of and Risk Factors for Coronavirus Infection in Health Care Workers: A Living Rapid Review. Ann. Intern Med. 2020, 173, 120-136. [CrossRef]

18. Hajure, M.; Tariku, M.; Bekele, F.; Abdu, Z.; Dule, A.; Mohammedhussein, M.; Tsegaye, T. Attitude Towards COVID-19 Vaccination Among Healthcare Workers: A Systematic Review. Infect. Drug Resist. 2021, 14, 3883-3897. [CrossRef]

19. El-Sokkary, R.H.; El Seifi, O.S.; Hassan, H.M.; Mortada, E.M.; Hashem, M.K.; Gadelrab, M.; Tash, R.M.E. Predictors of COVID-19 vaccine hesitancy among Egyptian healthcare workers: A cross-sectional study. BMC Infect. Dis 2021, 21, 762. [CrossRef]

20. Kukreti, S.; Lu, M.Y.; Lin, Y.H.; Strong, C.; Lin, C.Y.; Ko, N.Y.; Chen, P.L.; Ko, W.C. Willingness of Taiwan's Healthcare Workers and Outpatients to Vaccinate against COVID-19 during a Period without Community Outbreaks. Vaccines 2021, 9, 246. [CrossRef]

21. Gagneux-Brunon, A.; Detoc, M.; Bruel, S.; Tardy, B.; Rozaire, O.; Frappe, P.; Botelho-Nevers, E. Intention to get vaccinations against COVID-19 in French healthcare workers during the first pandemic wave: A cross-sectional survey. J. Hosp. Infect. 2021, 108, 168-173. [CrossRef]

22. Papagiannis, D.; Malli, F.; Raptis, D.G.; Papathanasiou, I.V.; Fradelos, E.C.; Daniil, Z.; Rachiotis, G.; Gourgoulianis, K.I. Assessment of Knowledge, Attitudes, and Practices towards New Coronavirus (SARS-CoV-2) of Health Care Professionals in Greece before the Outbreak Period. Int. J. Environ. Res. Public Health 2020, 17, 4925. [CrossRef] 
23. Kose, S.; Mandiracioglu, A.; Sahin, S.; Kaynar, T.; Karbus, O.; Ozbel, Y. Vaccine hesitancy of the COVID-19 by health care personnel. Int. J. Clin. Pract. 2020, 75, e13917. [CrossRef]

24. Alvarado-Socarras, J.L.; Vesga-Varela, A.L.; Quintero-Lesmes, D.C.; Fama-Pereira, M.M.; Serrano-Diaz, N.C.; Vasco, M.; CarballoZarate, V.; Zambrano, L.I.; Paniz-Mondolfi, A.; Rodriguez-Morales, A.J. Perception of COVID-19 Vaccination Amongst Physicians in Colombia. Vaccines 2021, 9, 287. [CrossRef]

25. Szmyd, B.; Karuga, F.F.; Bartoszek, A.; Staniecka, K.; Siwecka, N.; Bartoszek, A.; Błaszczyk, M.; Radek, M. Attitude and Behaviors towards SARS-CoV-2 Vaccination among Healthcare Workers: A Cross-Sectional Study from Poland. Vaccines 2021, 9, 218. [CrossRef]

26. Qattan, A.M.N.; Alshareef, N.; Alsharqi, O.; Al Rahahleh, N.; Chirwa, G.C.; Al-Hanawi, M.K. Acceptability of a COVID-19 Vaccine Among Healthcare Workers in the Kingdom of Saudi Arabia. Front. Med. 2021, 8, 644300. [CrossRef]

27. Spinewine, A.; Petein, C.; Evrard, P.; Vastrade, C.; Laurent, C.; Delaere, B.; Henrard, S. Attitudes towards COVID-19 Vaccination among Hospital Staff-Understanding What Matters to Hesitant People. Vaccines 2021, 9, 469. [CrossRef]

28. Petravic, L.; Arh, R.; Gabrovec, T.; Jazbec, L.; Rupcic, N.; Staresinic, N.; Zorman, L.; Pretnar, A.; Srakar, A.; Zwitter, M.; et al. Factors Affecting Attitudes towards COVID-19 Vaccination: An Online Survey in Slovenia. Vaccines 2021, 9, 247. [CrossRef]

29. Lin, C.; Tu, P.; Beitsch, L.M. Confidence and Receptivity for COVID-19 Vaccines: A Rapid Systematic Review. Vaccines 2020, 9, 16. [CrossRef]

30. Humer, E.; Jesser, A.; Plener, P.L.; Probst, T.; Pieh, C. Education level and COVID-19 vaccination willingness in adolescents. Eur. Child Adolesc. Psychiatry 2021, 1-3, online ahead of print. [CrossRef]

31. Biasio, L.R.; Bonaccorsi, G.; Lorini, C.; Pecorelli, S. Assessing COVID-19 vaccine literacy: A preliminary online survey. Hum. Vaccines Immunother. 2021, 17, 1304-1312. [CrossRef]

32. Ledda, C.; Costantino, C.; Cuccia, M.; Maltezou, H.C.; Rapisarda, V. Attitudes of Healthcare Personnel towards Vaccinations before and during the COVID-19 Pandemic. Int. J. Environ. Res. Public Health 2021, 18, 2703. [CrossRef]

33. Dzieciolowska, S.; Hamel, D.; Gadio, S.; Dionne, M.; Gagnon, D.; Robitaille, L.; Cook, E.; Caron, I.; Talib, A.; Parkes, L.; et al Covid-19 vaccine acceptance, hesitancy, and refusal among Canadian healthcare workers: A multicenter survey. Am. J. Infect. Control 2021, 49, 1152-1157. [CrossRef]

34. Sallam, M. COVID-19 Vaccine Hesitancy Worldwide: A Concise Systematic Review of Vaccine Acceptance Rates. Vaccines 2021, 9, 160. [CrossRef] [PubMed]

35. Biswas, N.; Mustapha, T.; Khubchandani, J.; Price, J.H. The Nature and Extent of COVID-19 Vaccination Hesitancy in Healthcare Workers. J. Community Health 2021, 46, 1244-1251. [CrossRef] [PubMed]

36. Dini, G.; Toletone, A.; Sticchi, L.; Orsi, A.; Bragazzi, N.L.; Durando, P. Influenza vaccination in healthcare workers: A comprehensive critical appraisal of the literature. Hum. Vaccines Immunother. 2018, 14, 772-789. [CrossRef] [PubMed]

37. Huang, K.; Lin, S.-W.; Sheng, W.-H.; Wang, C.-C. Influenza vaccination and the risk of COVID-19 infection and severe illness in older adults in the United States. Sci. Rep. 2021, 11, 11025. [CrossRef]

38. Riccò, M.; Cattani, S.; Casagranda, F.; Gualerzi, G.; Signorelli, C. Knowledge, attitudes, beliefs and practices of occupational physicians towards vaccinations of health care workers: A cross sectional pilot study in North-Eastern Italy. Int. J. Occup. Med. Environ. Health 2017, 30, 775-790. [CrossRef]

39. Loulergue, P.; Moulin, F.; Vidal-Trecan, G.; Absi, Z.; Demontpion, C.; Menager, C.; Gorodetsky, M.; Gendrel, D.; Guillevin, L.; Launay, $\mathrm{O}$. Knowledge, attitudes and vaccination coverage of healthcare workers regarding occupational vaccinations. Vaccine 2009, 27, 4240-4243. [CrossRef]

40. Di Martino, G.; Di Giovanni, P.; Di Girolamo, A.; Scampoli, P.; Cedrone, F.; D’Addezio, M.; Meo, F.; Romano, F.; Di Sciascio, M.B.; Staniscia, T. Knowledge and Attitude towards Vaccination among Healthcare Workers: A Multicenter Cross-Sectional Study in a Southern Italian Region. Vaccines 2020, 8, 248. [CrossRef]

41. Dolan, P.; Hallsworth, M.; Halpern, D.; King, D.; Metcalfe, R.; Vlaev, I. Influencing behaviour: The mindspace way. J. Econ. Psychol. 2012, 33, 264-277. [CrossRef]

42. Meyer, M.N.; Gjorgjieva, T.; Rosica, D. Trends in Health Care Worker Intentions to Receive a COVID-19 Vaccine and Reasons for Hesitancy. JAMA Netw. Open 2021, 4, e215344. [CrossRef]

43. Verger, P.; Dubé, E. Restoring confidence in vaccines in the COVID-19 era. Expert Rev. Vaccines 2020, 19, 991-993. [CrossRef]

44. Gadoth, A.; Halbrook, M.; Martin-Blais, R.; Gray, A.; Tobin, N.H.; Ferbas, K.G.; Aldrovandi, M.G.M.; Rimoin, M.A.W. Crosssectional Assessment of COVID-19 Vaccine Acceptance Among Health Care Workers in Los Angeles. Ann. Intern. Med. 2021, 174, 882-885. [CrossRef]

45. Detoc, M.; Bruel, S.; Frappe, P.; Tardy, B.; Botelho-Nevers, E.; Gagneux-Brunon, A. Intention to participate in a COVID-19 vaccine clinical trial and to get vaccinated against COVID-19 in France during the pandemic. Vaccine 2020, 38, 7002-7006. [CrossRef]

46. Garrett, L. COVID-19: The medium is the message. Lancet 2020, 395, 942-943. [CrossRef]

47. World Medical Association. World Medical Association Declaration of Helsinki. Ethical principles for medical research involving human subjects. Bull. World Health Organ. 2001, 79, 373-374. 